\title{
Functional gait disorders
}

\section{A sign-based approach}

Jorik Nonnekes, MD, PhD, Evžen Růžička, MD, DSc, Tereza Serranová, MD, PhD, Stephen G. Reich, MD, Bastiaan R. Bloem, MD, PhD, and Mark Hallett, MD

Neurology ${ }^{\circledR}$ 2020;94:1093-1099. doi:10.1212/WNL.0000000000009649

\section{Correspondence}

Dr. Nonnekes

jorik.nonnekes@

radboudumc.nl

MORE ONLINE

$\checkmark$ Videos

Functional gait disorders are common in clinical practice. They are also usually disabling for affected individuals. The diagnosis is challenging because no single walking pattern is pathognomonic for a functional gait disorder. Establishing a diagnosis is based not primarily on excluding organic gait disorders but instead predominantly on recognizing positive clinical features of functional gait disorders, such as an antalgic, a buckling, or a waddling gait. However, these features can resemble and overlap with organic gait disorders. It is therefore necessary to also look for inconsistency (variations in clinical presentation that cannot be reconciled with an organic lesion) and incongruity (combination of symptoms and signs that is not seen with organic lesions). Yet, these features also have potential pitfalls as inconsistency can occur in patients with dystonic gait or those with freezing of gait. Similarly, patients with dystonia or chorea can present with bizarre gait patterns that may falsely be interpreted as incongruity. A further complicating factor is that functional and organic gait disorders may coexist within the same patient. To improve the diagnostic process, we present a sign-based approachsupported by videos-that incorporates the diverse clinical spectrum of functional gait disorders. We identify 7 groups of supportive gait signs that can signal the presence of functional gait disorders. For each group of signs, we highlight how specific clinical tests can bring out the inconsistencies and incongruencies that further point to a functional gait disorder.

From the Department of Rehabilitation (I.N.), Radboud University Medical Centre, Donders Institute for Brain, Cognition and Behaviour, Centre of Expertise for Parkinson \& Movement Disorders; Department of Rehabilitation (I.N.), Sint Maartenskliniek, Nijmegen, the Netherlands; Department of Neurology and Centre of Clinical Neuroscience (E.R., T.S.), First Faculty of Medicine and General University Hospital, Charles University, Prague, Czech Republic; Department of Neurology (S.G.R.), The University of Maryland School of Medicine, Baltimore, MD; Department of Neurology (B.R.B.), Radboud University Medical Centre, Donders Institute for Brain, Cognition and Behaviour, Centre of Expertise for Parkinson \& Movement Disorders, Nijmegen, the Netherlands; andNational Institute of Neurological Disorders and Stroke (M.H.), Bethesda, MD.

Go to Neurology.org/N for full disclosures. Funding information and disclosures deemed relevant by the authors, if any, are provided at the end of the article. 


\section{Glossary}

DYT = dystonia type.

Functional gait disorders are both common and disabling. Depending on the clinical setting, $2 \%-20 \%$ of patients referred to movement disorders outpatient clinics have a functional movement disorder, ${ }^{1}$ and $40 \%$ of these patients have gait abnormalities without a structural lesion. ${ }^{2,3}$ It is important to timely recognize the features of a functional gait as approximately $12 \%$ of patients across all neurologic disease categories have a functional overlay. ${ }^{4}$ However, many clinicians find these functional gait disorders difficult to diagnose. They are often seen together with other functional movement disorders, although pure functional gait disorders occur in approximately $6 \%-8.5 \%$ of patients with functional neurologic disorders. ${ }^{2,3}$ When present together with other functional signs, proper recognition of a functional gait pattern is often very helpful in establishing the functional nature of the overall presentation, particularly when this is less obvious from the other neurologic signs. ${ }^{5}$

For several reasons, the term functional gait disorder is preferred over psychogenic gait disorder. First, psychological distress is not always evident, ${ }^{6}$ and functional gait disorders are often diagnosed in the absence of obvious precipitating stressors. Indeed, psychological stressors are now considered only as risk factors and not as essential causative triggers. ${ }^{7}$ Second, because acceptance of the diagnosis is essential for successful treatment, the more descriptive term functional gait disorders is preferred over psychogenic gait disorder, which has a negative connotation for many patients. ${ }^{8}$ For these reasons, the Diagnostic and Statistical Manual of Mental Disorders V (DSM-V) now uses the term Functional Neurological Symptom Disorders instead of Psychogenic Neurological Disorders. Moreover, the DSM-V diagnosis no longer relies on the presence of obvious psychological stressors. ${ }^{9}$ Importantly, functional neurologic symptoms (including functional gait disorders) are not thought to be produced intentionally and are therefore distinct from malingering and factitious disorder.

Several reviews have described the clinical phenomenology and treatment of functional movement disorders, ${ }^{8,10,11}$ but these only touched briefly on the spectrum and diagnosis of functional gait disorders. In this video-illustrated review, we describe a practical sign-based approach to functional gait disorders, aiming to improve the diagnostic process in daily clinical practice.

\section{Diagnosing a functional gait disorder}

Diagnosing a functional gait disorder is challenging for several reasons. First, there is not a single pathognomonic gait pattern. ${ }^{12}$ Functional gait disorders are often equated with bizarre clinical features, but this is a diagnostic pitfall because organic gait disorders can also produce bizarre gait patterns, as may occur in patients with choreatic or dystonic gait. Second, functional gait disorders can present with clinical features that resemble organic gait disorders. For example, a buckling gait (the knees giving way) is a common phenotype of a functional gait, but can also occur in patients with negative myoclonus of the lower extremities. Third, the presence of an organic gait disorder does not exclude the coexistence of a superimposed functional component and vice versa; when there is an obvious functional gait disorder, there might be some underlying organic disease as well. ${ }^{13}$ It can therefore be helpful to perform ancillary testing to rule out concurrent underlying organic neurologic disorders. However, the diagnosis of a clinically established functional movement disorder itself relies primarily on recognizing characteristic supportive features, which includes an inconsistency and incongruence with organic gait disorders, and not by simply ruling out, to the extent possible, an organic gait disorder. ${ }^{14}$

An example of inconsistency is an unexplained variability in gait disorder severity over time. Some patients can walk in daily life situations but are unable to walk during the physical examination. ${ }^{10}$ Family members may sometimes comment about a different walking pattern they are seeing during the examination compared with the gait pattern that is present at home. In addition, some patients manifest marked walking difficulties while being observed, but move remarkably better during spontaneous movements, e.g., in the examination room ${ }^{15}$ of while getting dressed or undressed. Unexplained variability also includes spontaneous remissions or exacerbations over time and a lack of falls despite severe gait impairments. Another example of inconsistency is a mismatch between the objectively visible severity of the gait impairments and any self-reported limitations during activities of daily living. This discrepancy can be in either direction, i.e., severe gait impairment may be present during examination but without any limitations during activities of daily living, or severe restrictions in daily life activities may be reported in the presence of mild gait impairments. ${ }^{13}$

Incongruency involves a combination of symptoms and signs not seen in organic gait disorders. For example, a sudden onset or rapid progression of gait impairments is uncommon in the absence of trauma or a structural lesion. ${ }^{2}$ Delayed onset of gait impairment after a (minor) trauma is another example of incongruency. The incongruency can also be brought out by the neurologic examination. An example would be an antalgic gait in the absence of any pain or a buckling gait (knees giving way) in the presence of normal quadriceps strength. Another example is a scissoring gait in the absence of corticospinal tract signs (such as brisk reflexes and hip adductor spasticity). Occasionally, the pattern itself is simply incongruent with functioning of the nervous system, as in a reported patient with a recumbent gait who continued to make stepping movements with the legs even while lying down flat on her back with eyes closed. ${ }^{16}$ An improvement of the gait pattern when the patient is volitionally 
performing a dual task (either motor or cognitive in nature) is another sign of both inconsistency and incongruency.

\section{A sign-based diagnostic approach}

In daily clinical practice, the picture is often subtler than these examples, which makes it challenging to identify inconsistencies and incongruencies. To facilitate the diagnostic process, we present a sign-based diagnostic approach, which incorporates the diverse clinical spectrum of functional gait disorders. According to this approach, the presenting signs are taken as the starting point for a tailored search into the origin of the gait disorder (either functional or organic). Importantly, evaluation of gait, and the identification of abnormal gait signs, cannot take place in a small examination room, as this does not elicit all relevant features, so patients really need to be taken to the corridor. We propose that abnormal gait signs (such as scissoring of the legs, buckling of the knees, or inability to walk in a straight line) are first classified into 1 of 7 broad categories: (1) ataxic gait, (2) spastic gait, (3) weak gait, (4) antalgic gait, (5) parkinsonian gait, (6), hemiparetic gait, and (7) dystonic gait (table). These 7 categories are the result of several consensus meetings between the authors. The rest of the subsequent examination is used to evaluate specific gait and balance tests that can help to reveal inconsistencies or incongruencies (table).

We illustrate this sign-based approach here for only the first group of gait signs, namely ataxic gait, which may be cerebellar, sensory, vestibular, or functional in origin. Suggestive signs for an ataxic gait include variability in the base of support and stride, inability to walk in a straight line (sometimes with an excessive arm swing), and claims of poor balance (video 1). A commonly observed inconsistency in patients with functional gait disorders resembling ataxia is balance control that is actually much better than what is perceived by the patient. During straight walking, patients may seek support of chairs, doorposts, or walls (video 2 and video 3 ), but do not actually fall even when such support is absent. Moreover, patients with functional gait disorders often seek support by objects that are actually quite for away. As illustrated by video 2 and video 3 , these patients are crossing the hallway to reach for support. Patients with organic ataxia seek support as well, but typically avoid to stray far from their support, and are much less likely to keep crossing the hallway. In addition, most patients with functional gait disorders do not fall despite the presence of exaggerated truncal sway (video 4). In fact, many patients actually display an excellent balance. When performing a dual task or when running or walking backward, improvement of gait performance is often seen in patients with a functional gait. Alternatively, patients with functional gait may display an exaggerated performance during these gait and balance tests. Importantly, the gait pattern typically does not alter markedly during running, walking backward, or dual-task performance in patients with sensory, vestibular, or cerebellar ataxia. If anything, performance deteriorates further because such tests are more demanding, but the walking pattern remains consistent. Walking with eyes closed, on the other hand, will worsen the gait pattern in patients with sensory or vestibular ataxia, whereas improvement can be observed in patients with a functional gait pattern (but remember the patient with the recumbent gait where the functional nature was elicited mainly after eye closure). Eye closure will typically force patients with unilateral vestibular or cerebellar lesions to veer to one side, whereas patients with functional ataxia can be seen veering from side to side, even with eyes open (video 2 and video 3). Another useful gait and balance test that may reveal inconsistencies and incongruencies is tandem walking. Patients with an organic origin of their ataxia are unable to perform tandem gait without taking one or more side steps, whereas patients with a functional gait pattern resembling ataxia may perform the tandem gait without sidesteps or may even display scissoring (crossing of the legs) or an exaggerated performance with prolonged single-leg stance or windmill like movements of the arms, but without falling (video 5 and video 6). Patients with functional gait disorders may fall, but in an incongruent manner (e.g., slowly without injuring themselves; video 7).

The Romberg test may reveal inconsistencies and incongruencies as well. Patients with cerebellar ataxia often cannot participate in Romberg testing as maintaining balance with the feet together and eyes open is significantly impaired. The Romberg test is abnormal in both patients with sensory ataxia (together with an abnormal sensory examination) and patients with vestibular ataxia (who may manifest veering to the side of the lesion). Patients with functional gait ataxia may display a positive Romberg test in the absence of sensory abnormalities, or alternatively, often with exaggerated truncal sway but without falling. People without functional or organic disorders may occasionally have a positive Romberg if asked to simple stand with eyes closed; they may lose balance due to introspection about standing with eyes closed. To minimize this, continuing to engage the person in conversation during the Romberg test can minimize this problem.

Finally, the pull test can also be helpful. The test can obviously be abnormal in patients with an organic gait disorder, but most will make attempts to try and maintain their balance (either taking multiple steps or by hinging of the trunk). Patients with a functional gait can show excessive trunk sway without ever falling, or fall completely passively backward into the arms of the examiner, although balance appears otherwise much better during the remainder of the examination. ${ }^{16}$ Note that patients with advanced Parkinson disease and atypical parkinsonism can also show complete absence of balance corrections during the pull test, either because of marked postural instability or because freezing interferes with their ability to take corrective steps. ${ }^{17} \mathrm{~A}$ marked discrepancy between a severely abnormal pull test and a much better or even normal forward push test can also be helpful, ${ }^{16}$ although patients with Parkinson disease can also show such discrepancies.

\section{Potential pitfalls}

Care must be taken not to miss organic disorders that present with such inconsistencies. For example, improvement with walking 
Table Abnormalities observed during walking and supportive tests help to evaluate consistency and congruency

\begin{tabular}{|c|c|c|c|}
\hline Predominant sign & Supportive tests & $\begin{array}{l}\text { Inconsistency or incongruency } \\
\text { suggesting functional origin }\end{array}$ & Outcome suggesting organic origin \\
\hline \multirow{4}{*}{$\begin{array}{l}\text { 1. Variability in base of support or } \\
\text { inability to walk in a straight line, } \\
\text { often with excessive arm } \\
\text { movements and claims of poor } \\
\text { balance (ataxia) }\end{array}$} & Straight walking & $\begin{array}{l}\text { Veering from side to side (video } 2 \text { and } \\
\text { video 3). Patients showing better actual } \\
\text { balance then claimed. }\end{array}$ & $\begin{array}{l}\text { In unilateral vestibular ataxia and } \\
\text { unilateral cerebellar ataxia, patients } \\
\text { veer consistently in the direction } \\
\text { ipsilaterally to the lesion. }\end{array}$ \\
\hline & $\begin{array}{l}\text { Performing a dual task, } \\
\text { running or walking } \\
\text { backward }\end{array}$ & $\begin{array}{l}\text { Improvement or exaggerated } \\
\text { performance. }\end{array}$ & $\begin{array}{l}\text { The gait pattern does not alter } \\
\text { markedly in patients with ataxia. }\end{array}$ \\
\hline & Walking with eyes closed & $\begin{array}{l}\text { Improvement of the gait pattern. } \\
\text { Sometimes unveils a bizarre gait pattern. }\end{array}$ & $\begin{array}{l}\text { Sensory or vestibular ataxia worsens } \\
\text { when walking with eyes closed. }\end{array}$ \\
\hline & $\begin{array}{l}\text { Romberg test and sensory } \\
\text { examination }\end{array}$ & $\begin{array}{l}\text { Abnormal performance without } \\
\text { accompanying sensory abnormalities } \\
\text { in the legs. Alternatively, there can be } \\
\text { exaggerated truncal sway without } \\
\text { falling during the Romberg test. }\end{array}$ & $\begin{array}{l}\text { Normal performance in patients with } \\
\text { cerebellar ataxia. Abnormal } \\
\text { performance in patients with sensory } \\
\text { ataxia (together with abnormal } \\
\text { sensory examination) and in patients } \\
\text { with vestibular ataxia (veering to the } \\
\text { side of the lesion). }\end{array}$ \\
\hline
\end{tabular}

Tandem walking

\section{Scissoring (spasticity)}

Evaluation of leg muscle tone and strength and reflexes
No side steps, prolonged standing on 1 leg, scissoring, or exaggerated performance without falling (video 5 and video 6).

No adductor spasticity, normal leg reflexes, and no weakness (or giveaway weakness) in patients with functional gait.

Evaluation of standing posture and ability to rise from sit to stance
Inconsistencies in postural control during these tasks.

Unable to perform tandem gait without side steps.

Adductor and calf-muscle spasticity, muscle weakness, and brisk reflexes in patients with spastic paraparesis.

In patients with higher-level gait disorders, gait scissoring is part of a grossly abnormal postural control, i.e., typically also evident when arising from a chair or when standing still.

\section{Walking backward Disappearance of scissoring when} backward walking (video 12).

In patients with spastic paraparesis or higher-level gait disorders, scissoring persists when walking backward. Scissoring might disappear in patients with unilateral or bilateral dystonia of the lower extremities, as this can be task specific.

\begin{tabular}{lll}
\hline 3. The weak gait with knees giving & $\begin{array}{l}\text { Evaluation of muscle } \\
\text { way or Trendelenburg gait }\end{array}$ & No weakness (or give-away weakness) \\
(weakness) & gluteus medius)
\end{tabular}

Weakness of the quadriceps or gluteus medius. However, buckling of the knees is rarely seen in patients with quadriceps weakness as patients would fall when their knees buckle. Patients therefore apply compensatory strategies, including locking of the knees.

Knee buckling is consistently present during these tasks in patients with negative myoclonus. Lateral trunk movements are consistently present in patients with weakness of the gluteus medius.

Limping is consistently present. History taking and physical examination revea pain that can explain the limping gait. 16). No pain to explain the limping gait. Give-way weakness with positive Hoover/abductor sign can be found

\begin{tabular}{llll}
\hline $\begin{array}{l}\text { 4. Antalgic gait. Asymmetrically } \\
\text { reduced stance phase (limping) }\end{array}$ & $\begin{array}{l}\text { Tandem gait, running, } \\
\text { performing a dual task } \\
\text { while walking, walking with } \\
\text { eyes closed, and walking } \\
\text { backward }\end{array}$ & $\begin{array}{l}\text { There is an inexplicable variability } \\
\text { when performing these tasks (video } \\
\text { 16). No pain to explain the limping gait. } \\
\text { Give-way weakness with positive } \\
\text { Hoover/abductor sign can be found }\end{array}$ & $\begin{array}{l}\text { Limping is consistently present. History } \\
\text { taking and physical examination reveal } \\
\text { pain that can explain the limping gait. }\end{array}$ \\
\hline $\begin{array}{l}\text { 5. Excessive slowness, sometimes } \\
\text { with start hesitancy (bradykinesia) }\end{array}$ & Straight walking & Prolonged single leg stance time. & Increase in double support time. \\
\hline & $\begin{array}{l}\text { Evaluation of muscle tone } \\
\text { and movement amplitude }\end{array}$ & $\begin{array}{l}\text { Bradykinesia and rigidity are not } \\
\text { consistently present. Tremor is } \\
\text { distractible and variable in frequency. } \\
\text { Incongruent pattern of freezing, often }\end{array}$ & $\begin{array}{l}\text { Bradykinesia, rigidity, and } \\
\text { nondistractible resting tremor in } \\
\text { gait is typically seen when turning and } \\
\text { when initiating gait, and episodes are } \\
\text { typically brief (seconds). }\end{array}$ \\
\hline a minute or longer).
\end{tabular}


Table Abnormalities observed during walking and supportive tests help to evaluate consistency and congruency (continued)

\begin{tabular}{|c|c|c|c|}
\hline Predominant sign & Supportive tests & $\begin{array}{l}\text { Inconsistency or incongruency } \\
\text { suggesting functional origin }\end{array}$ & Outcome suggesting organic origin \\
\hline & Pull test & $\begin{array}{l}\text { Excessive trunk sway without falling or } \\
\text { falling passively backward, although } \\
\text { balance appears otherwise much } \\
\text { better during the remainder of the } \\
\text { examination. }\end{array}$ & $\begin{array}{l}\text { Small balance correcting steps, forcing } \\
\text { patients to take more than } 2 \text { steps. } \\
\text { Severely affected patients take no } \\
\text { correcting steps at all. }\end{array}$ \\
\hline \multirow[t]{2}{*}{ 6. Dragging (hemiparesis) } & $\begin{array}{l}\text { Evaluation of leg muscle } \\
\text { tone and muscle strength }\end{array}$ & $\begin{array}{l}\text { Spasticity is not found. Give-way } \\
\text { weakness with positive Hoover sign or } \\
\text { abductor sign can be found. }\end{array}$ & $\begin{array}{l}\text { Spasticity and paresis are present in } \\
\text { patients with a unilateral upper motor } \\
\text { neuron lesion. }\end{array}$ \\
\hline & $\begin{array}{l}\text { Tandem gait, running, } \\
\text { performing a dual task } \\
\text { while walking, walking with } \\
\text { eyes closed, and walking } \\
\text { backward }\end{array}$ & $\begin{array}{l}\text { There is an inexplicable variability when } \\
\text { performing these tasks (video 17). }\end{array}$ & $\begin{array}{l}\text { Consistent presentation over time and } \\
\text { across tests. }\end{array}$ \\
\hline \multirow[t]{2}{*}{$\begin{array}{l}\text { 7. Abnormal posturing of the leg or } \\
\text { trunk (dystonia) }\end{array}$} & $\begin{array}{l}\text { Walking backward or } \\
\text { sideways }\end{array}$ & $\begin{array}{l}\text { Disappearance of abnormal posturing } \\
\text { (video 18). }\end{array}$ & $\begin{array}{l}\text { Posturing is consistently present in } \\
\text { patients with an upper motor neuron } \\
\text { lesion. Posturing might disappear during } \\
\text { backward or sideways walking in patients } \\
\text { with dystonia, as this can be task specific. }\end{array}$ \\
\hline & $\begin{array}{l}\text { Evaluation of muscle tone } \\
\text { and contractures around } \\
\text { the ankle and tarsal joints }\end{array}$ & $\begin{array}{l}\text { No abnormalities. Alternatively, there } \\
\text { can be fixed plantar flexion and } \\
\text { inversion, with rapid onset, which } \\
\text { cannot be easily overcome with } \\
\text { passive manipulation. Contractures } \\
\text { can be present. }\end{array}$ & $\begin{array}{l}\text { Contractures and spasticity can be } \\
\text { present in patients with abnormal } \\
\text { posturing due to an upper motor } \\
\text { neuron lesion. }\end{array}$ \\
\hline
\end{tabular}

backward can occur in patients with dystonic gait (reflecting the task specificity of the problem, which is typical for dystonia $)^{18}$ (video 8), whereas marked improvement with running can occur in patients with freezing of gait. Patients with freezing can also show many other inconsistencies, when using rather well-preserved alternative gait patterns (such as scissoring of the legs or walking with skating movements) that are less automated, more goal directed, or externally driven and hence less dependent on defective basal ganglia circuitries. ${ }^{19}$ Moreover, patients with dystonia can episodically apply gestes antagonistes, which are compensatory motor or sensory tricks to overcome or reduce dystonia. ${ }^{20}$ Video 9 illustrates a patient with Parkinson disease with a Pisa syndrome triggered by exposure to a dopamine receptor agonist (consistently present when walking forward, backward, and when running), which improved on touching the head. These gestes antagonistes may also incorrectly be classified as an inconsistent gait feature. Another published Parkinson patient revealed a highly unusual pattern (that might easily be mistaken for a functional sign), namely alleviation of freezing of gait when he gently pressed his temples, either as sensory trick or, most likely, as an attentional mechanism. ${ }^{21}$ Chorea may also be misinterpreted as functional, and this applies to levodopa-induced dyskinesias, which can present with rather bizarre gait patterns - an example is the stamping gait produced by biphasic dyskinesias with pronounced dystonic elements (such as stepping with kicks or high knee elevations), as can be seen particularly in younger men with Parkinson disease. ${ }^{22}$ Although these levodopa-induced dyskinesias can appear outright bizarre, they are remarkably stereotyped and consistent in their presentation, without alterations in presentation over time or with specific tests such as running or walking backward. ${ }^{22}$ This again serves to emphasize that a bizarre gait pattern should not be equated with functional gait disorders.
Another fairly common organic gait disorder that might be mistaken for functional is the walking pattern in patients with frontal lobe dysfunction (e.g., due to a frontal lesion), which can produce a variety of gait patterns, including a highly variable gait pattern with increased truncal sway and gait scissoring. ${ }^{12}$ To complicate matters further, the gait pattern might also change with disease progression, which can incorrectly be interpreted as an inconsistent feature. Helpful features here include the consistency of the gait pattern across different gait tests, as well as the presence of other frontal release signs during neurologic examination.

Several rare organic gaits might be mistaken for having a functional nature. One is the hobby horse gait, which has been described in patients with dystonia type 4 (DYT 4). ${ }^{23}$ These patients walk as if riding a hobby horse, with a stiff-legged skipping gait. The pattern is, however, very consistent and may be accompanied by other signs of dystonia. Ref. 23 contains an illustrative video demonstrating this gait type. Another example is an unusual clasp-knife type of gait in a patient with DYT1 dystonia, with sudden hinging of the trunk on gait initiation, and even when producing stepping movements while standing in place (video 10). In this case, the consistency of the abnormal movements (during walking, running, backward walking, and stepping in place) and the presence of other dystonic features (elicited also during the seated examination) pointed to the organicity of the gait abnormalities. Another rare organic gait that might be misinterpreted occurs in patients with stiff-person syndrome. These patients typically present with stiffness and spasms in the lumbar region and lower extremities, ${ }^{24,25}$ and gait is usually deliberately very slow and broad based in an effort to prevent falling (video 11). Pattern recognition is important 
here, as the presentation - which also includes the characteristic lumbar hyperlordosis - is in fact both congruent and consistent. Another rare yet organic gait is knee buckling in patients with negative myoclonus, as may occur after cerebral hypoxia, hepatic encephalopathy or in patients with Huntington disease. The negative myoclonus causes a bouncing gait characterized by postural lapses. In this situation, the bounces are usually very quick and look very different from the much slower and prolonged buckling seen in functional disorders (which actually require a very good quadriceps strength). Cataplexy in patients with narcolepsy can occasionally also lead to buckling of the knees, although such spells are typically much briefer and are linked to specific triggers such as laughter. However, a gait pattern with staggering to both sides and buckling of the knees has been described in a patient with excessive daytime sleepiness due to status cataplecticus. ${ }^{26}$ Ref. 24 contains an illustrative video demonstrating this gait type. Many of these rare neurologic conditions are usually accompanied by other clinical features that would help to make the diagnosis.

\section{Supportive signs}

As functional gait disorders often occur together with other types of functional disorders, it is helpful to search for additional inconsistent or incongruous neurologic findings. ${ }^{2}$ Moreover, several supportive signs can offer diagnostic support in patients with a functional gait disorder. ${ }^{27}$ A useful one is the expressive behavior including breath-holding and grimacing while standing or walking (originally labeled as huffing and puffing sign, although we prefer expressive behavior, as this does not have a negative connotation). ${ }^{28}$ This sign has an excellent specificity but poor sensitivity: in a cohort of 131 patients with a functional gait disorder (with the absence of pain), expressive behavior was present in 44\%, whereas it was minimal or absent in 37 patients with an organic gait disorder. ${ }^{28}$ A recent study reported an even lower sensitivity: expressive behavior was only present in 14 of 60 patients $(23 \%)$ with a functional gait disorder. ${ }^{3}$

Another supportive sign is the chair sign. In a small study with 9 patients with a functional gait disorder, 8 patients were able to propel themselves better when seated on an office chair with wheels compared with regular walking, which was not present in 9 control patients with parkinsonism. ${ }^{29}$ This test needs confirmation in larger studies, as we suspect that some organic gait disorders (such as task-specific gait dystonia or freezing of gait) may also yield a positive chair test, thus diminishing its specificity.

\section{Conclusion}

We have described a sign-based approach to better diagnose functional gait disorders. In this sign-based approach, presenting gait signs are taken as the starting point for a tailored search into the origin of the gait disorder. After identification of the presenting gait signs, clinical tests can subsequently bring out inconsistencies and incongruencies that may point out to a functional gait disorder. We hope that this will help clinicians during the diagnostic process in their daily clinical practice.

\section{Study funding}

No targeted funding reported.

\section{Disclosure}

J. Nonnekes is supported by a center of excellence grant of the Parkinson's Foundation through the Radboudumc Centre of Expertise for Parkinson \& Movement Disorders. E. Růžička was supported by the Ministry of Health of the Czech Republic, grant AZV ČR 16-29651. T. Serranová was supported by the Ministry of Health of the Czech Republic, grant AZV ČR 1629651. S.G. Reich reports no relevant disclosures. B.R. Bloem is supported by a center of excellence grant of the Parkinson's Foundation through the Radboudumc Centre of Expertise for Parkinson \& Movement Disorders. M. Hallett is supported by the National Institute of Neurological Disorders and Stroke Intramural Program. Go to Neurology.org/N for full disclosures.

\section{Publication history}

Received by Neurology January 6, 2020. Accepted in final form April 7, 2020.

\section{Appendix Authors}

\begin{tabular}{|c|c|c|}
\hline Name & Location & Contribution \\
\hline $\begin{array}{l}\text { Jorik } \\
\text { Nonnekes, } \\
\text { MD, PhD }\end{array}$ & $\begin{array}{l}\text { Radboud University Medical } \\
\text { Centre; Donders Institute for } \\
\text { Brain, Cognition and Behaviour; } \\
\text { Department of Rehabilitation; } \\
\text { Centre of Expertise for Parkinson } \\
\text { \& Movement Disorders; } \\
\text { Nijmegen, The Netherlands. } \\
\text { Department of Rehabilitation, Sint } \\
\text { Maartenskliniek, Nijmegen, The } \\
\text { Netherlands. }\end{array}$ & $\begin{array}{l}\text { Collecting videos } \\
\text { and drafting the } \\
\text { manuscript }\end{array}$ \\
\hline $\begin{array}{l}\text { Evžen } \\
\text { Rư̌zička, } \\
\text { MD, DSc }\end{array}$ & $\begin{array}{l}\text { Department of Neurology and } \\
\text { Centre of Clinical Neuroscience, } \\
\text { First Faculty of Medicine and } \\
\text { General University Hospital, } \\
\text { Charles University, Prague, Czech } \\
\text { Republic }\end{array}$ & $\begin{array}{l}\text { Collecting videos } \\
\text { and drafting the } \\
\text { manuscript }\end{array}$ \\
\hline $\begin{array}{l}\text { Tereza } \\
\text { Serranová, } \\
\text { MD, PhD }\end{array}$ & $\begin{array}{l}\text { Department of Neurology and } \\
\text { Centre of Clinical Neuroscience, } \\
\text { First Faculty of Medicine and } \\
\text { General University Hospital, } \\
\text { Charles University, Prague, Czech } \\
\text { Republic }\end{array}$ & $\begin{array}{l}\text { Collecting videos } \\
\text { and drafting the } \\
\text { manuscript }\end{array}$ \\
\hline $\begin{array}{l}\text { Stephen G. } \\
\text { Reich, MD }\end{array}$ & $\begin{array}{l}\text { Department of Neurology, The } \\
\text { University of Maryland School of } \\
\text { Medicine, Baltimore, Maryland, } \\
\text { USA }\end{array}$ & $\begin{array}{l}\text { Collecting videos } \\
\text { and drafting the } \\
\text { manuscript }\end{array}$ \\
\hline $\begin{array}{l}\text { Bastiaan R. } \\
\text { Bloem, MD, } \\
\text { PhD }\end{array}$ & $\begin{array}{l}\text { Radboud University Medical } \\
\text { Centre; Donders Institute for } \\
\text { Brain, Cognition and Behaviour; } \\
\text { Department of Neurology; Centre } \\
\text { of Expertise for Parkinson \& } \\
\text { Movement Disorders; Nijmegen, } \\
\text { The Netherlands }\end{array}$ & $\begin{array}{l}\text { Collecting videos } \\
\text { and drafting the } \\
\text { manuscript }\end{array}$ \\
\hline $\begin{array}{l}\text { Mark } \\
\text { Hallett, MD }\end{array}$ & $\begin{array}{l}\text { National Institute of Neurological } \\
\text { Disorders and Stroke, Bethesda, } \\
\text { MD, USA }\end{array}$ & $\begin{array}{l}\text { Collecting videos } \\
\text { and drafting the } \\
\text { manuscript }\end{array}$ \\
\hline
\end{tabular}




\section{References}

1. Edwards MJ, Bhatia KP. Functional (psychogenic) movement disorders: merging mind and brain. Lancet Neurol 2012;11:250-260.

2. Baik JS, Lang AE. Gait abnormalities in psychogenic movement disorders. Mov Disord 2007;22:395-399.

3. Baizabal-Carvallo JF, Alonso-Juarez M, Jankovic J. Functional gait disorders, clinical phenomenology, and classification. Neurol Sci 2019;41:911-915.

4. Stone J, Carson A, Duncan R, et al. Which neurological diseases are most likely to be associated with "symptoms unexplained by organic disease." J Neurol 2012;259: 33-38.

5. Balint B, van Winsen LML, Bhatia KP, Bloem BR. Psychogenic movement disorders: gait is a give-away!. Mov Disord Clin Prac 2014;1:110-111.

6. Nicholson TR, Aybek S, Craig T, et al. Life events and escape in conversion disorder. Psychol Med 2016;46:2617-2626.

7. Ludwig L, Pasman JA, Nicholson T, et al. Stressful life events and maltreatment in conversion (functional neurological) disorder: systematic review and meta-analysis of case-control studies. Lancet Psychiatry 2018;5:307-320.

8. Morgante F, Edwards MJ, Espay AJ. Psychogenic movement disorders. Continuum (Minneap Minn) 2013;19:1383-1396.

9. American Psychiatric Association. Diagnostic and Statistical Manual of Mental Disorders, 5th ed. Washington, DC: American Psychiatric Association; 2013.

10. Espay AJ, Aybek S, Carson A, et al. Current concepts in diagnosis and treatment of functional neurological disorders. JAMA Neurol 2018;75:1132-1141.

11. Hallett M. Psychogenic movement disorders. Eur Neuropsychopharm 2015;25:S153

12. Nonnekes J, Goselink RJM, Ruzicka E, Fasano A, Nutt JG, Bloem BR. Neurological disorders of gait, balance and posture: a sign-based approach. Nat Rev Neurol 2018; 14:183-189.

13. Hayes MW, Graham S, Heldorf P, de Moore G, Morris JGL. A video review of the diagnosis of psychogenic gait: appendix and commentary. Mov Disord 1999;14: 914-921.

14. Gupta A, Lang AE. Psychogenic movement disorders. Curr Opin Neurol 2009;22: $430-436$.

15. Araujo R, van de Warrenburg B, Lang A, Lees A, Bloem B. The Waiting Room: neurological observations made outside the movement disorder specialist's consulting office. Pract Neurol 2019;19:295-301.
16. Boogaarts HD, Abdo WF, Bloem BR. "Recumbent" gait: relationship to the phenotype of "astasia-abasia?" Mov Disord 2007;22:2121-2122.

17. Nonnekes J, Goselink R, Weerdesteyn V, Bloem BR. The retropulsion test: a good evaluation of postural instability in Parkinson's disease? J Parkinsons Dis 2015;5: 43-47.

18. Albanese A. The clinical expression of primary dystonia. J Neurol 2003;250: $1145-1151$.

19. Nonnekes J, Ruzicka E, Nieuwboer A, Hallett M, Fasano A, Bloem BR. Compensation strategies for gait impairments in Parkinson disease: a review. JAMA Neurol 2019;76: $718-725$.

20. Ramos VF, Karp BI, Hallett M. Tricks in dystonia: ordering the complexity. J Neurol Neurosurg Psychiatry 2014;85:987-993.

21. Nonnekes J, Janssen S, Bloem BR. Superficial brain stimulation to overcome freezing of gait in Parkinson disease. Neurology 2017;88:1681-1682.

22. Ruzicka E, Zarubova K, Nutt JG, Bloem BR. "Silly walks" in Parkinson's disease: unusual presentation of dopaminergic-induced dyskinesias. Mov Disord 2011;26: 1782-1784.

23. Wilcox RA, Winkler S, Lohmann K, Klein C. Whispering dysphonia in an Australian family (DYT4): a clinical and genetic reappraisal. Mov Disord 2011;26:2404-2408.

24. McKeon A, Robinson MT, McEvoy KM, et al. Stiff-man syndrome and variants: clinical course, treatments, and outcomes. Arch Neurol 2012;69:230-238.

25. Brown P, Rothwell JC, Marsden CD. The stiff leg syndrome. J Neurol Neurosurg Psychiatry 1997;62:31-37.

26. Simon DK, Nishino $S$, Scammell TE. Mistaken diagnosis of psychogenic gait disorder in a man with status cataplecticus ("limp man syndrome"). Mov Disord 2004;19: 838-840.

27. Daum C, Gheorghita F, Spatola M, et al. Interobserver agreement and validity of bedside "positive signs" for functional weakness, sensory and gait disorders in conversion disorder: a pilot study. J Neurol Neurosur Ps 2015;86:425-430.

28. Laub HN, Dwivedi AK, Revilla FJ, Duker AP, Pecina-Jacob C, Espay AJ. Diagnostic performance of the "huffing and puffing" sign in functional (psychogenic) movement disorders. Mov Disord Clin Prac 2015;2:29-32.

29. Okun MS, Rodriguez RL, Foote KD, Fernandez HH. The "chair test" to aid in the diagnosis of psychogenic gait disorders. Neurologist 2007;13:87-91.

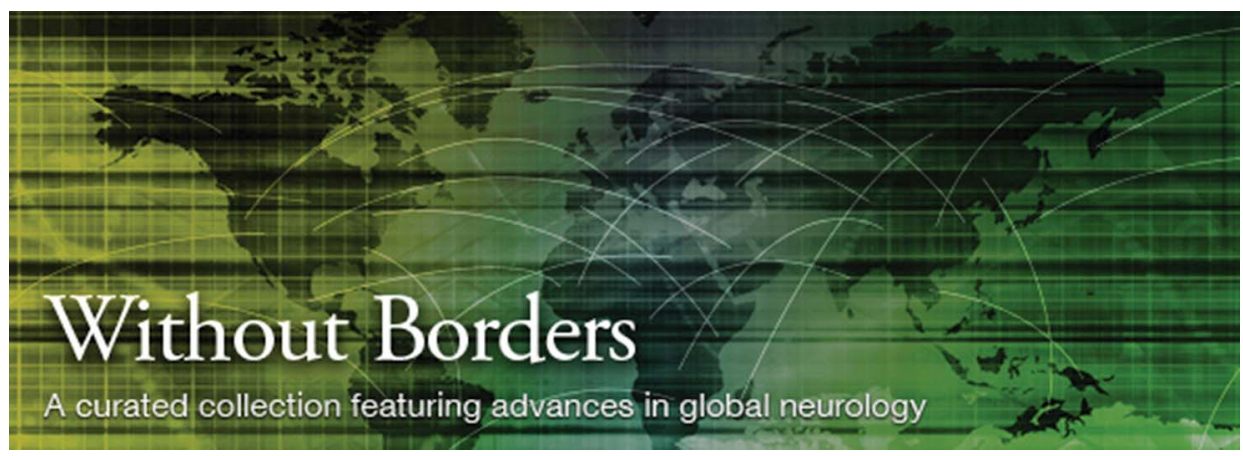

\section{Without Borders - A curated collection featuring advances in global neurology}

This Neurology ${ }^{\circledR}$ special interest website is the go-to source for tracking science and politics of neurology beyond the United States, featuring up-to-the-minute blogs, scholarly perspectives, and academic review of developments and research from Neurology journals and other sources. Curated by Gretchen L. Birbeck, MD, MPH.

\section{Expand your world view at Neurology.org/woborders.}




\section{Neurology}

\section{Functional gait disorders: A sign-based approach \\ Jorik Nonnekes, Evzen Ruzicka, Tereza Serranová, et al.}

Neurology 2020;94;1093-1099 Published Online before print June 1, 2020

DOI 10.1212/WNL.0000000000009649

\section{This information is current as of June 1, 2020}

\section{Updated Information \& Services}

\section{References}

Citations

Subspecialty Collections

Permissions \& Licensing

Reprints including high resolution figures, can be found at: http://n.neurology.org/content/94/24/1093.full

This article cites 28 articles, 5 of which you can access for free at: http://n.neurology.org/content/94/24/1093.full\#ref-list-1

This article has been cited by 4 HighWire-hosted articles: http://n.neurology.org/content/94/24/1093.full\#\#otherarticles

This article, along with others on similar topics, appears in the following collection(s):

\section{Clinical neurology examination}

http://n.neurology.org/cgi/collection/clinical_neurology_examination

\section{Conversion}

http://n.neurology.org/cgi/collection/conversion

Gait disorders/ataxia

http://n.neurology.org/cgi/collection/gait_disorders_ataxia

Information about reproducing this article in parts (figures,tables) or in its entirety can be found online at:

http://www.neurology.org/about/about_the_journal\#permissions

Information about ordering reprints can be found online:

http://n.neurology.org/subscribers/advertise

Neurology ${ }^{\circledR}$ is the official journal of the American Academy of Neurology. Published continuously since 1951, it is now a weekly with 48 issues per year. Copyright Copyright ( 2020 The Author(s). Published by Wolters Kluwer Health, Inc. on behalf of the American Academy of Neurology.. All rights reserved. Print ISSN: 0028-3878. Online ISSN: 1526-632X.

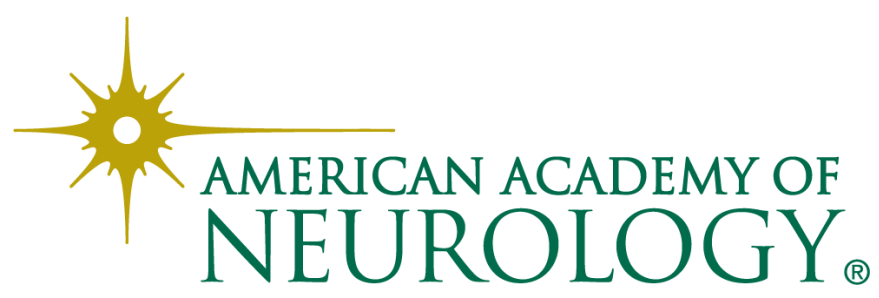

